\title{
Arte, cultura e política na história do rap nacional
}

[ Art, culture and politics in the history of Brazilian rap

\section{Bráulio Roberto de Castro Loureiro}

TEPERMAN, Ricardo. Se liga no som: as transformações do rap no Brasil. São Paulo: Claro Enigma, 2015.

Como fruto de pesquisa de mestrado no Departamento de Antropologia Social da Universidade de São Paulo, o livro Se liga no som: as transformações do rap no Brasil, do antropólogo e músico Ricardo Teperman, se insere num campo temático que vem sendo marcado pelo volume crescente de produções. Se na década de 1990 a análise teórica sobre o rap e o hip-hop no Brasil dava seus primeiros passos², nos últimos quinze anos o gênero musical e o movimento cultural que o abrange atraíram a atenção de um número significativo de pesquisadores - acadêmicos e não acadêmicos. Estes os têm investigado a partir de múltiplos enfoques, notadamente aspectos étnicos, etários, artísticos, históricos, culturais, educacionais e políticos.

Transitar pela história do rap nacional a fim de problematizar lugares-comuns, registrar mudanças e analisar significados é a proposta central do livro de Teperman. Nas palavras do autor: "flagrar as transformações das maneiras de fazer, ouvir e falar sobre rap no Brasil” (p. Io).

DoI: http://dx.doi.org/Io.II606/issn.23I6-90IX.voi63Ip235-24I

I Doutor em Ciência Política pela Universidade Estadual de Campinas (Unicamp).

2 Menciono os trabalhos de Elaine N. Andrade (Movimento negro juvenil: um estudo de caso sobre jovens rappers de São Bernardo do Campo. Dissertação (Mestrado). São Paulo: Universidade de São Paulo, I996; e Rap e educação, rap é educação. São Paulo: Summus, I999), Spensy K. Pimentel (O livro vermelho do hip hop. Trabalho de conclusão de curso. São Paulo: Universidade de São Paulo, I997), Micael Herschmann (Abalando os anos 90 - funk e hip-hop: globalização, violência e estilo de vida. Rio de Janeiro: Rocco, I997), Francisco J. Damasceno ( $O$ movimento hip-hop organizado do Ceará / MH2O-CE (I990-I995). Dissertação (Mestrado). São Paulo: Pontifícia Universidade Católica, I997), José C. Silva (Rap na cidade de São Paulo: música, etnicidade e experiência urbana. Tese (Doutorado). Campinas: Universidade Estadual de Campinas, I998), Maria E. Guimarães (Do samba ao rap: a música negra no Brasil. Tese (Doutorado). Campinas: Universidade Estadual de Campinas, I998) e Marco A. Tella (Atitude, arte, cultura e autoconhecimento: o rap como voz da periferia. Dissertação (Mestrado). São Paulo: Pontifícia Universidade Católica, 2000). 
Para tanto, ao longo de aproximadamente I50 páginas, nos apresenta um material organizado em quinze seções harmonicamente encadeadas e cujo conteúdo aborda questões que vão das primeiras formas de manifestação do rap em território nacional, marcadas pelo protesto contundente da chamada "velha escola", às novas e multifacetadas vertentes do rap que ganham espaço em tempos de ampliação do acesso à internet e se caracterizam, de modo geral, por maior flexibilidade no trato com a indústria fonográfica e a grande mídia. Tudo isso sem deixar de lidar com as contradições e ambiguidades de uma expressão artística e cultural historicamente atravessada, entre outros dilemas, pela tensão entre a rua e o mercado.

De início, Teperman põe sob exame duas noções amplamente aceitas no universo do hip-hop: I) o significado da palavra "rap" enquanto sigla para rhythm and poetry - ritmo e poesia -; 2) o distrito nova-iorquino do Bronx como local de surgimento do gênero musical. Sobre a primeira, recorda que o uso da palavra "rap", há tempos presente nos dicionários de inglês, remonta ao século XIV. Referindo-se a algo como "bater" ou "criticar", antes mesmo da eclosão da música rap o termo já aparecia no contexto de jogos de improviso e insulto verbal, prática corriqueira entre negros de algumas cidades dos Estados Unidos. A hipótese mais provável seria, então, a de que o próprio uso da palavra "rap" tenha culminado na nomenclatura do gênero, fato que não eliminaria a relevância e o impacto de sua vinculação a uma sigla que, além de transitar com facilidade entre línguas latinas, desafia concepções conservadoras ao sustentar o rap como expressão musical e poética. Como sublinha o autor, "Não é pouca coisa, e não é à toa que a etimologia de rap como sigla para ritmo e poesia "colou”' (p. I6). A respeito da segunda noção, Teperman ressalta que a reflexão sobre a geografia do rap ganha sentido quando não desconsidera ondas de imigração fundamentais para a constituição do fenômeno: a dos negros africanos trazidos como escravos para o trabalho nas Américas e a dos latinos de países da América Central que, após a Segunda Guerra, emigraram para os Estado Unidos em busca de melhores condições de vida. Se os primeiros e seus descendentes contribuíram decisivamente para o surgimento de gêneros como blues, jazz, rock, soul, funk, além do próprio rap, os últimos - especialmente os jamaicanos - levaram ao Bronx o costume das festas de rua movidas a equipamentos de som e microfones acoplados a caminhões e carros.

Tais observações são o ponto de partida para um mergulho do autor nas fases iniciais de constituição do rap nos Estados Unidos, que compreendem as rimas improvisadas dos MCs nas block parties do início dos anos I970, as primeiras gravações musicais difundidas pela indústria fonográfica e a influência da atuação político-cultural do DJ Afrika Bambaataa e das composições de grupos como Public Enemy na afirmação do caráter de protesto social e racial do gênero musical. Vale lembrar que Bambaataa, ex-membro da Black Spades - gangue do South Bronx -, teve a iniciativa de articular as expressões presentes nas festas de rua - DJ, MC, break e grafite-num movimento mais amplo, o hip-hop. Inspirado por referências da luta por direitos civis nos Estados Unidos e preocupado com a situação de pobreza, opressão racial e violência juvenil nos guetos, fundou em I973 a Universal Zulu Nation, primeiro coletivo de hip-hop a mesclar elementos artísticos e conhecimentos políticos num trabalho comunitário. Como disse Nino Brown, "A gente nunca pode esquecer o nome desse cara. Porque ele sofreu muitas perseguições. Até hoje a Zulu Nation 
Universal [sic] é perseguida pelo FBI, pela CIA e pela SWAT, porque simplesmente o governo americano não suporta a Zulu ali no Bronx há mais de 30 anos. E isso é uma luta!"3

Já no contexto brasileiro, Teperman nos apresenta a edificação desse que é considerado por muitos o "quinto elemento do hip-hop" - o conhecimento, a politização - quando resgata as raízes do rap nacional no contexto dos bailes black em cidades como São Paulo e Rio de Janeiro nas décadas de I970 e I980, quando detalha a movimentação de b.boys e $M C s$ nos encontros na estação São Bento do metrô e na Praça Roosevelt entre I985 e I988, no centro de São Paulo, e quando registra a propagação de posses e coletivos de hip-hop na periferia paulistana a partir dos anos I990. E contra a argumentação por vezes pejorativa que trata o desenvolvimento do rap nacional como simples reprodução do que foi criado nos Estados Unidos, o autor, apoiado em Roberto Schwarz, sustenta que dificilmente pode haver cópia sem interpretação, de tal maneira que conceitos de cultura que fixam no espaço e no tempo a existência de um "original" tenderiam a não apreender adequadamente dinâmicas que fazem parte da vida cultural. "A relação dos rappers brasileiros com seus pares do hemisfério norte é descomplexada, ao mesmo tempo que cheia de admiração. Mais do que o tabu da cópia, o rap brasileiro nos anos I980 buscou lidar com o desafio de inventar sua própria tradição" (p. 64).

De fato, se por aqui o rap sofreu influência do rap estadunidense, este não deixou de ser experimentado em conexão com a particularidade do contexto social, cultural e artístico em que respiravam os jovens das periferias brasileiras. É importante notar que a difusão do rap para além das fronteiras dos Estados Unidos também se refere à propagação entre subalternos de algo que cativa, diz respeito e faz sentido. Uma rede comunicacional de periferia para periferia forjada sobre a experiência comum que normalmente conjuga exploração de classe e opressão étnico-racial. A esse respeito, lembro aqui de Tony Mitchell, organizador de um trabalho que traz informações de outros doze estudiosos do rap e do hip-hop em 25 países de cinco continentes. Mitchell acentua que a análise da ocorrência do rap no mundo não deve ignorar sua manifestação - muitas vezes numa dimensão comunitária e fora do campo de cobertura dos grandes veículos de comunicação - como expressão da realidade social de oprimidos de contextos variados, ou seja, como canal capaz de associar apropriações e sincretismos que transcendem a simples assimilação musical, linguística e cultural do rap estadunidense4.

É consenso que, no caso brasileiro, o grupo Racionais MC's foi aquele que mais influiu na constituição da tradição do rap nacional, cujo traço marcante é o grito-denúncia do conjunto de espoliações que negros e pobres sofrem cotidianamente nas cidades. Considerado por muitos a voz dos periféricos do Brasil, o Racionais alcançou todas as regiões do país e, numa forma estética apurada, criticou a violência que permeia a sociedade brasileira. Ainda hoje, camisetas com estampas do grupo vestem milhares de ouvintes. E são usadas, muitas vezes, como armaduras para as

3 Nino Brown em Toni C. É tudo nosso: o hip-hop fazendo história. Documentário. São Paulo, 2007.

4 MITCHELL, Tony. Global noise: rap and hip-hop outside the USA. Middletown: Wesleyan University Press, 2001. 
lutas amargas da vida do povo. O rap do grupo foi ouvido e ecoou em bairros, favelas e prisões, aparecendo realmente como consta em "Vida loka I": o "cântico dos louco e dos romântico”s. É o que também constata Teperman, que destaca a abrangência do impacto das produções de Mano Brown, Edi Rock, KL Jay e Ice Blue no universo dos jovens pobres brasileiros. Na entrada dos anos I990, num contexto marcado pelo arrefecimento do movimento popular, por expressivos índices de violência urbana e por certa diluição mercadológica da unidade político-estética que a MPB conquistara em décadas anteriores, o Racionais teria despontado, "captando a experiência brasileira com sua lente original” (p. 67). Ao contestar a visão cordial e conciliatória que estrutura o mito da democracia racial brasileira, o grupo teria sido capaz de criar um campo de identificação não mais ancorado na imagem do pobre alegre e festivo, mas do preto, pobre e periférico que não aceita a subjugação e revida.

As letras do Racionais atacam a perpetuação da desigualdade, o racismo, a violência policial e outras mazelas da sociedade brasileira. E o fazem assumindo um posicionamento claro numa estrutura de classes, em franca oposição ao que eles próprios entendem como classe dominante (p. 78)

A capacidade do grupo em articular questão racial e de classe numa postura agressiva e intransigente, na leitura de Teperman, confere à prática inicial do Racionais um caráter revolucionário. Afinal, os artistas da periferia paulistana chegaram a um lugar de destaque no cenário cultural nacional recusando os símbolos da burguesia, propondo enfrentamentos e se mantendo independentes dos mecanismos hegemônicos de produção. Isso, no entanto, sem deixar de experimentar constantemente "a contradição entre ser uma cultura de rua e, ao mesmo tempo, ser um valioso produto de mercado" (p. 73, grifo do autor).

Atento aos posicionamentos históricos do Racionais diante de tal contradição, Teperman identifica na trajetória do grupo certa mudança de teor, especialmente a partir de Nada como um dia após o outro dia, álbum de 2002. "Não é à toa que, apesar da produção constante de faixas lançadas individualmente, de projetos paralelos e da gravação de um DVD ao vivo, um novo disco de inéditas - intitulado Cores e valores - só viria no final de 2014, depois de doze anos” (p. 84). A emblemática entrevista de Mano Brown à revista Rolling Stone, em 2009, na qual o rapper já expõe um discurso mais maleável, a criação da produtora Boogie Naipe e a contratação de uma assessoria de imprensa, a participação de Brown na versão de “Umbabarauma”, de Jorge Ben Jor, em campanha promocional da Nike para a Copa do Mundo de 20Io, o lançamento de músicas com levadas mais dançantes, além da própria investida dos demais membros do grupo em projetos individuais 6 , teriam aproximado o Racionais da chamada "nova

5 Racionais MC's. “Vida loka I”. In: Nada como um dia após o outro dia. CD. São Paulo: Cosa Nostra, 2002b.

6 Tais iniciativas também seriam marcadas por maior flexibilidade dos artistas com relação a parcerias e à mídia. Teperman menciona a ida de Edi Rock ao programa Caldeirão do Huck, na Rede Globo, em 2013, para o lançamento do disco solo Contra nós ninguém será e a participação de Ice Blue no rap "Estilo gangstar", de Túlio Dek. O videoclipe de "Estilo gangstar" estreou no Fantástico e apresenta elementos da vertente conhecida como "rap ostentação". 
escola" do rap nacional. A inflexão convertera a postura revolucionária, marca da primeira fase do grupo, numa perspectiva radical. Cabe esclarecer que a noção "radical" é colhida por Teperman nas formulações de Antonio Candido, referindo-se à posição que, mesmo apontando para transformações na sociedade, se identifica apenas parcialmente com os interesses das classes trabalhadoras, tendendo, inclusive, à conciliação.

O espírito de cisão expresso em canções como "Hey boy" e "Da ponte pra cá", nas quais o Racionais se refere ao playboy de maneira dura - "Não tem nada pra você aqui não, seu otário!"7, "Nós aqui, vocês lá, cada um no seu lugar, entendeu?"8 -, de fato, se atenuou. Em entrevista à Revista Fórum, em 2013, indagado sobre ser ouvido pela classe média, Mano Brown respondeu: "Vejo com respeito, ouço crítica, elogio, converso, é importante ouvir o que eles dizem. Acho da hora que eles venham falar, até pra explicar minhas teorias”. E, tratando mais diretamente de sua suposta mudança, asseverou: "A juventude precisa de rapidez, mobilidade de ideias. Não dá pra ficar na mesma ideia todo dia. Seria uma atitude até covarde, fácil, ficar jogando mais lenha na fogueira. Então, você tem de buscar outras ideias, que passam pela raça também, com certeza".

A "nova escola" seria a geração do rap nacional que surge no fim dos anos 2000 - em boa medida vinculada às batalhas de MCs - e que se caracteriza por uma mudança de posicionamento diante da geração das décadas de I980 e I990, a "velha escola”. Maior escolaridade, maior acesso a bens de consumo, flexibilidade no trato com a grande mídia e considerável traquejo comercial seriam traços comuns a esses novos artistas e diferenciariam as escolas. Rappers como Emicida, RAPadura, Criolo, Projota e Kamau são alguns dos nomes citados por Teperman como representantes desse novo contexto. Jovens da periferia, ouvintes do rap dos anos I990, que em tempos de ampliação do acesso à internet e a tecnologias em geral compõem, cantam e administram seu trabalho numa perspectiva de inserção e participação nos canais centrais da música brasileira. Nesse sentido, a empresa Laboratório Fantasma, criada por Emicida e seus familiares para organizar e gerenciar a carreira do rapper - e de outros artistas -, ganha destaque nas páginas do livro como expressão do pensamento "empreendedor" que definiria a atual geração do rap nacional.

O talento de Emicida como artista, sua inteligência no uso dos novos canais de comunicação possibilitados com a internet, a habilidade em ampliar e aprofundar redes de relações pessoais e profissionais, o tino comercial e a enorme capacidade de trabalho dos irmãos Evandro e Leandro e sua equipe fizeram da empresa o mais bem-sucedido negócio na história do hip-hop nacional. (p. 147.)

Evitando o ponto de vista que tende a atribuir à produção cultural da periferia uma homogeneidade nem sempre concretamente existente - algo não tão incomum

7 Racionais MC’s. “Hey boy”. In: Holocausto urbano. CD. São Paulo: Unimar, I990.

8 Racionais MC’s. “Da ponte pra cá”. In: Nada como um dia após o outro dia. CD. São Paulo: Cosa Nostra, $2002 a$.

9 Mano Brown em CARVALHO, Igor; FARIA, Glauco e ROVAI, Renato. O novo velho Mano Brown. Entrevista de Mano Brown a Igor Carvalho, Glauco Faria e Renato Rovai. Revista Fórum, edição I20, 2013. 
quando o assunto é rap -, Teperman, naquele que é o seu capítulo mais extenso, trata do caráter plural da manifestação do rap no Brasil. Diversidade territorial e de estilos constituída, vale ressaltar, desde a década de I980. Se a capital paulista e os grupos paulistanos tiveram importância significativa na tradição do rap nacional, é preciso não negligenciar as inúmeras experiências no âmbito do rap e do hip-hop que ocorreram paralelamente - ou eclodiram com certa proximidade - em outras localidades do país. Por meio do texto de Teperman, transitamos por distintas "cenas" do rap nacional, deparando-nos com o papel fundamental que rádios comunitárias, jornais de bairro e fanzines de diversas cidades tiveram na difusão inicial do gênero musical. A particularidade do rap em cidades nordestinas também é abordada pelo autor, que identifica, por exemplo, na obra do grupo recifense Faces do Subúrbio, criado em I992, a presença de ritmos regionais como a embolada. Nesse circuito, ainda somos levados àquela que é considerada por muitos uma cena de grande relevância no trajeto do rap no Brasil: a capital Brasília, precisamente, suas cidades-satélite. Por ali, desde os anos de 1980 já se via expressão artística de b.boys e MCs. Estes últimos produziram e difundiram um rap marcado por batidas pesadas e cujo conteúdo comumente encontra-se ligado a temas como violência urbana, criminalidade e drogas, tendência conhecida como "gangsta rap".

Fato é que a pluralidade já existente se acentuou a partir da década de 2000. Subgêneros cada vez mais distintos teriam se constituído na esteira do aparecimento de recursos tecnológicos que facilitaram a produção e a difusão musical. E sites e redes sociais contribuído para a disseminação de informações do universo do rap por diferentes regiões do país. Viu-se, assim, o fortalecimento de tendências já existentes, como o "rap gospel" e o rap cantado por mulheres, e o surgimento de vertentes novas, como o rap cantado por indígenas e o controverso "rap ostentação". Todavia, como o próprio autor já havia sinalizado ao confrontar aspectos revolucionários e radicais, a popularização e pluralização vistas no contexto da "nova escola", ainda que contribuintes do fortalecimento do gênero musical e da articulação de novas bandeiras político-ideológicas à expressão, teriam sido acompanhadas pela suavização do teor crítico historicamente presente nas canções do rap brasileiro. No centro do problema estariam as tensões relativas à aproximação de boa parte desses artistas dos círculos dominantes da produção cultural. "Nas letras mais recentes de Emicida, o posicionamento de classe não se apagou, mas perdeu a contundência” (p. I40-I4I), observa o autor.

Não obstante, a noção final é que, a despeito da "radicalização" de sua face hegemônica, o rap ainda preserva força e potencial questionador. Um entendimento que atravessa o livro de Teperman é o de que o rap é, ao mesmo tempo, música e mais que música. Concebida não apenas como objeto estético restrito a elementos internos, mas percebida no âmbito de sua existência social, a música, reforça o autor, sempre "está no mundo", modificando a realidade e sendo modificada por ela. De todo modo, em tempos de mercantilização da vida e de certa glamorização da periferia, fica sempre o receio de que a expressão artística que tanto falou e ainda fala aos subalternos brasileiros tenha cada vez mais a sua vitalidade crítica esvaída pela exploração comercial. 


\section{REFERÊNCIAS BIBLIOGRÁFICAS}

ANDRADE, Elaine N. Movimento negro juvenil: um estudo de caso sobre jovens rappers de São Bernardo do Campo. Dissertação (Mestrado). São Paulo: Universidade de São Paulo, I996. . Rap e educação, rap é educação. São Paulo: Summus, I999.

CARVALHO, Igor; FARIA, Glauco e ROVAI, Renato. O novo velho Mano Brown. Entrevista de Mano Brown a Igor Carvalho, Glauco Faria e Renato Rovai. Revista Fórum, edição I20, 2013.

DAMASCENO, Francisco J. O movimento hip-hop organizado do Ceará/ MH2O-CE (I990-I995). Dissertação (Mestrado). São Paulo: Pontifícia Universidade Católica, I997.

GUIMARÃES, Maria E. Do samba ao rap: a música negra no Brasil. Tese (Doutorado). Campinas: Universidade Estadual de Campinas, I998.

HERSCHMANN, Micael (org.). Abalando os anos 90 - funk e hip-hop: globalização, violência e estilo de vida. Rio de Janeiro: Rocco, I997.

MITCHELL, Tony. Global noise: rap and hip-hop outside the USA. Middletown: Wesleyan University Press, 200I.

PIMENTEL, Spensy K. O livro vermelho do hip hop. Trabalho de conclusão de curso. São Paulo: Universidade de São Paulo, I997.

RACIONAIS MC’s. “Hey boy”. In: CD. Holocausto urbano. São Paulo: Unimar, I990.

. "Da ponte pra cá". In: Nada como um dia após o outro dia. CD. São Paulo: Cosa Nostra, $2002 a$.

. "Vida loka I”. In: Nada como um dia após o outro dia. CD. São Paulo: Cosa Nostra, 2002b.

SILVA, José C. Rap na cidade de São Paulo: música, etnicidade e experiência urbana. Tese (Doutorado). Campinas: Universidade Estadual de Campinas, I998.

TELLA, Marco A. Atitude, arte, cultura e autoconhecimento: o rap como voz da periferia. Dissertação (Mestrado). São Paulo: Pontifícia Universidade Católica, 2000.

TONI C. É tudo nosso: o hip-hop fazendo história. Documentário. São Paulo, 2007. 